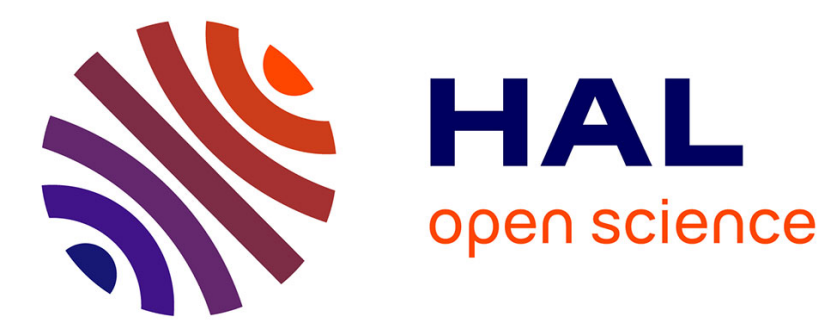

\title{
Maurice Allais on the quantity theory of money: the ontological restatement \\ Ramzi Klabi
}

\section{To cite this version:}

Ramzi Klabi. Maurice Allais on the quantity theory of money: the ontological restatement. Journal of Economic Methodology, 2019, 26 (4), pp.361-379. 10.1080/1350178X.2018.1546885 . hal-02417403

\section{HAL Id: hal-02417403 https://hal-amu.archives-ouvertes.fr/hal-02417403}

Submitted on 15 Jun 2020

HAL is a multi-disciplinary open access archive for the deposit and dissemination of scientific research documents, whether they are published or not. The documents may come from teaching and research institutions in France or abroad, or from public or private research centers.
L'archive ouverte pluridisciplinaire HAL, est destinée au dépôt et à la diffusion de documents scientifiques de niveau recherche, publiés ou non, émanant des établissements d'enseignement et de recherche français ou étrangers, des laboratoires publics ou privés. 


\title{
Maurice Allais on the quantity theory of money: the ontological restatement
}

\author{
Ramzi Klabi
}

Aix-Marseille Univ., CNRS, EHESS, Centrale Marseille, AMSE

Mail : ramzi.klabi@gmail.com 


\title{
Maurice Allais on the quantity theory of money: the ontological restatement
}

\begin{abstract}
This paper is about a little known part of Allais' oeuvre, namely his restatement of the quantity theory of money. It shows that this restatement contains an original refinement of the notion of stability of the relative demand for money. To explain this refinement, this essay investigates Allais' concept of psychological time -a concept strongly emphasised but not duly examined by most of his commentators. It shows how Allais' restatement of the quantity theory amounts -in the final analysisto a theory of time. It explores an analogy, Allais mentioned, between his quantity theory and the theory of relativity in physics, revealing thereby the ontological nature of this restatement.
\end{abstract}

Keywords: Maurice Allais, the quantity theory of money, psychological time, relativity, ontology. 


\section{Introduction}

In 1965, Maurice Allais proposed an original restatement of the quantity theory of money. It is the Hereditary and Relativistic (HR) theory of the demand for money. Published a decade after Friedman's restatement (Friedman, 1956) and Cagan's model on the dynamics of hyperinflations (Cagan, 1956), the HR theory remained unknown. And it is no exaggeration to say that, when it comes to the literature on the history of the quantity theory, it is as if Allais' restatement did not occur.

Allais sought to explain cyclical fluctuations in aggregate nominal spending -instead of mere fluctuations in prices. Unlike traditional quantitativists, he assumed that the velocity of circulation of money is a variable magnitude ${ }^{1}$ and that fluctuations in aggregate nominal spending are to a large extent caused by changes in this magnitude. He sought therefore to model the variability of the money velocity with a single formulation capable of dealing with all the cases studied.

Taken at its face value, the HR theory -as presented by Allais- does not bring in its essence something new when compared to Friedman's restatement of the quantity theory. Both authors agree that the velocity of money should not be considered as a constant magnitude, but

\footnotetext{
${ }^{1}$ The idea of variability of the money velocity is an old one. Allais quoted Cantillon who, as early as 1755 , stated: "I have already noticed that an acceleration, or a greater pace, in the circulation of money in exchange is equivalent to an increase in the actual money, up to a certain degree". (Cantillon, R. (1755), Essai sur la nature du commerce, INED |1952], p. 90, cited by Allais, 1965, p. 30).
} 
as a stable function (Allais, 1965, p. 150; 1966, p. 1153). ${ }^{2}$ This account, however, does not pay due attention to Allais' conceptual framework, especially to his concept of psychological time.

Indeed, to construct his formulation, Allais introduced a psychological time scale and stated that the relative demand for money (i.e. the nominal demand for money in relation to the aggregate nominal spending -or the inverse of the money velocity ${ }^{3}$ ) is constant when referred to it. The concept of psychological time is based on the intuitive idea that durations which are equal along the physical time scale are not necessarily experienced as equal durations by the collectivity of economic agents. Whether or not that is the case depends on the economic context.

Eminent economists commented on the concept of psychological time and the role it plays in Allais' model. Cagan (1969) considered it as Allais' most distinctive contribution to monetary theory and to time series analysis in general (Cagan, 1969, p. 427). Friedman and Schwartz (1982) pointed out the relevance of Allais' time transformation in explaining the behaviour of economic agents. These comments capture the meaning of this time transformation, but do not reveal its scope. They paid no specific attention to the statement of invariance of the relative demand for money in psychological time, its status (hypothetical / conventional) and its implication on the way Allais' HR theory ought to be construed as a restatement of the quantity theory.

\footnotetext{
${ }^{2}$ This is indeed the gist of Friedman's restatement of the quantity theory. The latter argued that the velocity of money can be expressed as a stable function of a limited number of variables (i.e. a function whose form and parameters are invariant). The work of Friedman and Schwartz (1963) contributed very much to disseminating this idea of stability of the money velocity.

${ }^{3}$ Under the assumption that the nominal demand for money is nearly equal to the effective money balances (I will return to this point later).
} 
The notion of psychological time gained prominence in Barthalon (2014)'s book about Allais' theory of monetary dynamics. Barthalon intended to rehabilitate what he called "the theory of psychological time". ${ }^{4} \mathrm{He}$ is mainly aiming at showing that the HR theory contains an original theory of expectations under uncertainty. ${ }^{5}$ His analysis of the concept of psychological time refers to the intuitive idea of a context-dependent perception of time. It shows the importance of this concept and paved the way for further analysis of its place and scope in Allais' monetary theory.

This paper is an attempt to investigate Allais' restatement of the quantity theory to show that it contains an original refinement of the notion of stability of the money velocity, or -equivalently- that of the relative demand for money. This investigation is based on a thorough analysis of the concept of psychological time and the statement of invariance of the relative demand for money within its framework. I will show how Allais' restatement of the quantity theory amounts -in the final analysis- to a theory of time. And I will argue that it could be considered as an ontological restatement in that it mainly rests on a transformation of the ontology underlying the quantity theory.

The first section expounds the cornerstones of the HR theory and its formulation of the relative demand for money. It puts emphasis on the role played by the concept of psychological time in this formulation as perceived by Allais' commentators, namely Cagan (1969) and Friedman and Schwartz (1982).

The second section examines the status of the invariance of the relative demand for

\footnotetext{
${ }^{4}$ As announced in the subtitle of his book 'Reviving Allais' lost theory of psychological time'.

${ }^{5}$ One of his objectives is to show that Allais' theory of monetary dynamics contains assumptions and analytical tools that are liable to be transposed to financial markets and may contribute to modeling financial behavior (Barthalon, 2014, pp. xxxv-i).
} 
money in psychological time. It shows that Allais' theory explains the behaviour of the relative demand for money through the distortion of the ratio between physical time and psychological time. It goes beyond the intuitive idea of a context-dependent perception of time and explores an analogy mentioned by Allais between his theory and the theory of relativity in physics to point out the fundamental character of psychological time. It underscores thereby the ontological nature of Allais' restatement of the quantity theory.

\section{The hereditary and relativistic theory of the demand for money: an outline}

Before expounding the HR theory of the demand for money, it may help to take a look at its genesis which began quite before 1965. Indeed, in 1954, Allais proposed a model of the demand for money ${ }^{6}$ which is -mathematically- nearly similar to Cagan's celebrated model about the dynamics of hyperinflations (Cagan, 1956).

In Cagan's model, the real demand for money (i.e. the demand for cash balances in relation to the price level) is a decreasing function of the expected rate of change of the price level $(E(\mathrm{t}))$.

$$
\frac{M(t)}{P(t)}=e^{-\alpha E(t)-\gamma}
$$

$\alpha$ and $\gamma$ are two constant parameters.

The expression of $(E(t))$ is -in its cumulative form - that of a weighted average of the past rates of change of the price level with weighting coefficients that decrease exponentially at a constant rate - the coefficient of expectation $\beta$.

\footnotetext{
${ }^{6}$ This model was presented in a meeting of the Econometric Society (Uppsala, Aug, 1954) and published in (Allais, 1956).
} 


$$
E(t)=\frac{\int_{-\infty}^{\mathrm{t}} \mathrm{C}(\tau) \mathrm{e}^{-\beta(\mathrm{t}-\tau)} \mathrm{d} \tau}{\int_{-\infty}^{\mathrm{t}} \mathrm{e}^{-\beta(\mathrm{t}-\tau)} \mathrm{d} \tau}
$$

In Allais' 1954 model the relative demand for money (the demand for cash balances in relation to the aggregate nominal spending) is a decreasing function of what he called the psychological rate of expansion $(u(t))$.

$$
\frac{M_{D}(t)}{D(t)}=\phi_{0}(1-K u(t))
$$

$\phi_{0}$ and $K$ are two constant parameters.

The psychological rate of expansion $(u(t))$ is a weighted average of the past rates of growth in aggregate nominal spending with weighting coefficients that decrease exponentially at a constant rate - a rate of memory decay $\bar{\chi}$.

$$
u(t)=\frac{\int_{-\infty}^{t} x(\tau) e^{-\bar{\chi}(t-\tau)} d \tau}{\int_{-\infty}^{t} e^{-\bar{\chi}(t-\tau)} d \tau}
$$

At the empirical level, neither Allais nor Cagan managed to represent all the series considered with the same formulation characterised by, among other things, a constant rate of memory decay [coefficient of expectation]. Allais noticed that the rate of memory decay is higher the higher the average rate of expansion during the period considered. Furthermore, since there is an inverse relationship between the relative demand for money and the latter rate, Allais added that the rate of memory decay is the higher the lower the value of the relative demand for money (or the greater the velocity of circulation) (Allais, 1966, pp. 1125-1127, Allais, 1965, p. 42). 
Cagan too remarked on this relationship. Indeed, he observed in his study of hyperinflations that the coefficient of expectation increases as the hyperinflation becomes more intense (in other words, as the relative demand for money diminishes). Nevertheless, he did not take this observation into account in his model.

Allais was not content with this result. For him, the relative demand for money should be represented with a single formulation capable of dealing with all the cases studied. The quest for a single formulation was motivated by his conception of economics as a science:

Firstly, the prerequisite of any science is the existence of regularities which can be analyzed and forecast. This is for example the case in celestial mechanics. But it is also true of many economic phenomena. Indeed, their thorough analysis displays the existence of regularities which are just as striking as those found in the physical sciences. This is why Economics is a science and why this science rests on the same general principles and methods as the physical sciences. [...] It seems to me that, to a very large extent, the social sciences must, like the physical sciences, be based on the search for relationships and quantities invariant in time and in space (Allais, 1997, p. 7).

In the HR theory, Allais retained the hereditary feature of his 1954 model (i.e. the effect of the memory of the past rates of growth in aggregate nominal spending). In addition to that, he introduced an innovative concept of psychological time which played a key role in explaining the variability of the rate of memory decay in physical time and providing the single formulation of the relative demand for money he sought to obtain.

\subsection{The cornerstones of the hereditary and relativistic theory}

The first cornerstone of Allais' restatement of the quantity theory (Allais, 1965) is thus the idea that the behaviour of economic agents -insofar as their desire to hold money is concerned- is conditioned by their memory of past events. The influence of these events is more attenuated the more distant they are in the past. The fact that the HR theory grounds its analysis on the 
hereditary influence of the past does not mean that it denies the important role played by expectations. The HR theory

holds that any anticipation of the future is strongly influenced by the hereditary influence of the past, and that, this being so, it is this influence which is the motor force of the dynamic development of the economy, with anticipation of the future acting only as an intermediary factor (Allais, 1974, p. $323)$.

The second cornerstone of Allais' HR theory is the idea according to which time as experienced by economic agents depends on the course of economic events. Therefore, the physical time scale $(t)$-which is defined with regard to astronomic phenomena- is not necessarily the most relevant for the study of economic phenomena.

To take an extreme example, the psychological time scale in relation to physical time is not the same for the one who is sentenced to death and who will be executed within an hour and for the one who goes about his business peacefully in normal conditions. At the economic level, the time scale, evidently, cannot be the same for economic operators in a period where prices remain roughly constant during one or many years and in a period where prices change by the hour, as it was the case in the German hyperinflation of 1923 (Allais, 1965, p. 19).

A psychological time scale $\left(t^{\prime}\right)$, considered for the society as a whole (Allais, 1965, p.23), would thus be relevant for the study of monetary phenomena. Why? And, it could be said, what does the consideration of a time scale have to do with the theory of the demand for money?

Barthalon (2014, pp. 70-72) provides the following answer: A theory of the demand for money seeks to explain the variability of the money velocity. The latter is a frequency. It measures how often money changes hands during a certain period of calendar time. The rate at which the memory of past events fades (the rate of memory decay) is also a frequency. Both 
the money velocity and the rate of memory decay are the inverse of some durations. The HR theory suggests that both of them constitute with time three different facets of the same temporal mechanism. If one of these facets is explained the other two facets will be systematically explained.

The hereditary dependence of monetary behaviours with regard to past events and the consideration of a psychological time scale constitute the two pillars of the HR theory. Let us see how Allais formulated them respectively through the hereditary and relativistic postulates.

- The hereditary postulate: According to Allais, the behaviour of economic agents -insofar as their desire to hold money is concerned- depends on their overall appraisal of economic conjuncture. This appraisal is based on the past rates of growth in aggregate nominal spending $x(t)$. In fact,

[t]he feeling that the economy is prosperous results from the appearance of profits [...]. Rising aggregate expenditure brings about the appearance of profits, and thus gives rise to optimistic appraisal of the conjunctural situation. Assessment of the economic situation is thus tied to the rate of change of aggregate expenditure, and our appraisal today depends on the cumulative hereditary effect of past rates of growth of aggregate expenditure (Allais 1969, p. 444).

Allais defines the coefficient of psychological expansion $Z(t)$ as an index of the appraisal of economic conjuncture by the society as a whole. Its formulation is the embodiment of the hereditary idea. $Z(t)$ is indeed a weighted sum of all the past rates of growth in aggregate nominal spending. The weighting coefficients decline exponentially with time, which means that the influence of these past rates on the appraisal of economic conjuncture is more attenuated the more remote these rates are: 


$$
Z(t)=\int_{-\infty}^{t} x(\tau) e^{-\int_{\tau}^{t} \chi(u) d u} d \tau
$$

With $\quad x(t)=\frac{1}{D(t)} \frac{d D(t)}{d t}$

$\chi(t)$ is a rate of memory decay ${ }^{7}$ per unit of physical time. It is defined such that the effect of the decay of the memory of past events between $\tau$ and $t$ can be represented by the coefficient $e^{-\int_{\tau}^{t} \chi(u) d u} \cdot 8$

- The relativistic postulate: Allais states that a psychological time scale $\left(t^{\prime}\right)$ can be defined such that

(i) the rate of memory decay related to it, $\chi^{\prime}\left(t^{\prime}\right)$, is constant.

(ii) the quantity of oblivion ${ }^{9}$ related to an interval of psychological time is equal to the quantity of oblivion related to the corresponding interval of physical time.

$$
\chi^{\prime}\left(t^{\prime}\right) d t^{\prime}=\chi(t) d t
$$

\footnotetext{
${ }^{7}$ Let me note that the rate $\chi$ was called by Allais (1965) "taux d'oubli" in French, translated as "rate of forgetfulness" in English (Allais, 1966). This translation is not appropriate. It does not convey the meaning of this rate as the rate at which the memory of past events fades away. I chose, therefore, to call it "rate of memory decay", following Cagan (1969, p. 428) and Barthalon (2014).

${ }^{8}$ Suppose, for instance, a constant rate of memory decay of $0,4 \%$ per month. This means that the average length of collective memory is 250 months (or 20,83 years) and the weights given to the observations that are less than 250 months old account for $63.21 \%$ of the total weight given to past observations (This example is borrowed from Barthalon (2014, pp. 257-258)).

${ }^{9}$ The notion of 'quantity of oblivion' [quantité d'oubli] was used by Prat (1999, p. 193). It refers to the product $\chi(t) d t$ in physical time and to the product $\chi^{\prime}\left(t^{\prime}\right) d t^{\prime}$ in psychological time.
} 
The psychological time considered by Allais is not an individual psychological time. Rather, it is a "psychological time for a whole society" (Allais, 1965, p. 23). It is from the outset a collective concept. And the memory of past events to which it is related is a collective memory:

"[...] [T]he memory of past events can be handed down to us collectively through books, eyewitness accounts, or, less apparently but just as effectively, through the successive impact of an evolving social fabric. All these events, however remote, act on our contemporary psychological attitudes, even if we have never participated in or witnessed the events concerned" (Allais, 1974, p. 323).

\subsection{The HR formulation of the relative demand for money}

In Allais' theory, the central variable that describes the behaviour of economic agents, with respect to their desire to hold money, is the relative demand for money $\Phi_{D}(t)$ expressed by the ratio of the nominal demand for money $M_{D}(t)$ to the aggregate nominal spending $D(t)$ :

$$
\Phi_{D}(t)=\frac{M_{D}(t)}{D(t)}
$$

The relative demand for money, according to Allais (1965, p. 70), corresponds to $k$ of the celebrated Cambridge cash-balance equation. ${ }^{10}$ One should note however that there are some caveats to this correspondence. The first is that Allais assumes that the nominal demand for money $M_{D}(t)$ is not equal to the effective money balances $M(t)$. However, at any given moment, economic agents are in a position to adjust their money balances towards the desired

\footnotetext{
${ }^{10}$ The Cambridge cash-balance equation reads

$$
M=k P y
$$

where $M$ is the quantity of money in circulation, $P$ the level of prices, and $y$ the real income. $k$ is the ratio of the desired cash-balances. It is equal to the ratio of the quantity of money $M$ to the nominal income $P y$.
} 
level $M_{D}(t)$ (trough hoarding or dishoarding). This adjustment is never perfect, but the discrepancy between $M(t)$ and $M_{D}(t)$ is always relatively small (Allais, 1966, pp. 1137-1138), and we have

$$
M(t) \approx M_{D}(t)
$$

The second point is that $k$ is the inverse of the income-velocity of money while $\Phi_{D}$ is rather the inverse of the transaction-velocity. But since Allais assumes that the aggregate nominal spending is proportional to the aggregate nominal income, one can say that $\Phi_{D}$ is equal to the inverse of the income-velocity of money up to a constant.

The relative demand for money in Allais is not a constant magnitude. It is a variable which depends on the coefficient of psychological expansion $Z(t)$ in the following way:

$$
\Phi_{D}(t)=\Phi_{0} \Psi(Z(t))
$$

$\Phi_{0}$ is a constant representing the value of the relative demand for money in a stationary regime (i.e. for $Z(t)=0) .{ }^{11} \Psi(Z(t))$ is 'the function of desired money balances'. It is a logistic decreasing function of $Z(t)$. And it is an invariant function, independent of time and location:

$$
\Psi(Z(t))=\frac{1+b}{1+b e^{\alpha Z(t)}}
$$

$\alpha$ and $b$ are two parameters. Two psychological assumptions led Allais to the conclusion ${ }^{12}$

$$
\alpha=b=1
$$

This implies that

$$
\Psi(Z(t))=\frac{2}{1+e^{Z(t)}}
$$

\footnotetext{
${ }^{11}$ In a stationary regime, $D(t)$ is constant, then $x(t)=0$ and $Z(t)=0$.

${ }^{12}$ The asymptotic postulate and the postulate of psychological conjunctural symmetry (See Allais (1965, pp. 8284) and (1966, pp. 1135-1137)).
} 


$$
\text { where } Z(t)=\int_{-\infty}^{t} x(\tau) e^{-\int_{\tau}^{t} \chi(u) d u} d \tau
$$

The relative demand for money can thus be described as having two components:

(i) A structural component $\phi_{0},{ }^{13}$ the value of which corresponds to the relative demand for money in a period of psychological neutrality (i.e. in a stationary regime).

(ii) A psychological component captured by the function $\Psi(Z(t))$.

The presentation of the HR formulation is not yet complete. For, one of its most important and most commented features remains to be explained. It is the way Allais made the rate of memory decay $\chi$ varies in physical time.

The psychological time played a key role in determining the way the rate of memory decay varies in physical time. Indeed, we know from the relativistic postulate that the rate of memory decay varies along the physical time scale proportionally to the ratio $\left(d t^{\prime} / d t\right)$

$$
\begin{gathered}
\chi(\mathrm{t})=\chi^{\prime}\left(t^{\prime}\right) \frac{\mathrm{dt}^{\prime}}{\mathrm{dt}} \\
\text { (with } \chi^{\prime}\left(t^{\prime}\right) \text { constant, } \forall \mathrm{t}^{\prime} \text { ) }
\end{gathered}
$$

\footnotetext{
${ }^{13} \phi_{0}$ depends on the habits of payment and the structure of the production system (the length of the period of production) (Prat, 1999). It varies from one country to another. It is the only variable parameter. As for the three other parameters $\alpha, b$ and $\chi^{\prime}$ (which is equal to $\chi_{0}$, the rate of memory decay along the physical time scale in a stationary regime), they are psychological and assumed to be constant.
} 
The ratio $\left(d t^{\prime} / d t\right)$ is assumed to depend on the coefficient of psychological expansion $Z(t)$ in the following way ${ }^{14}$ :

$$
\frac{d t^{\prime}}{d t}=\frac{1+e^{Z(t)}}{2}
$$

This finally leads to the following expression of the rate of memory decay in physical time:

$$
\chi(\mathrm{t})=\chi^{\prime} \frac{1+e^{Z(t)}}{2}
$$

What does this practically mean?

Suppose that in a period of hyperinflation, the ratio $d t^{\prime} / d t$ reaches a value of 48 under the influence of an increasing $Z(t)$. This means that an astronomical day in this period of hyperinflation is, at the psychological level, experienced as 48 days of a period of stability (which is equivalent to saying that an astronomical day in a period of stability is experienced as half an hour of this period of hyperinflation). This also means that the rate of memory decay, while remaining constant in psychological time, is multiplied by 48 in physical time. ${ }^{15}$

The empirical fits of the HR formulation of the demand for money ${ }^{16}$ concerned different cases, running from periods of stability to episodes of hyperinflations. When he exposed his empirical results, Allais was keen to emphasise the main advances his HR formulation achieved especially compared to Cagan's model (Allais, 1966, 1986). This is important, since Allais' conceptual framework -incongruous with the standard approach (i.e. the Cambridgian tradition ${ }^{17}$ relayed by Keynes and Friedman, among others)- is less parsimonious than the one

\footnotetext{
${ }^{14}$ I will analyse the main assumptions and the process which led Allais to this relation in section 2 below.

15 This example is a modified version of the one given by Prat (1999, p. 185).

${ }^{16}$ Theses empirical fits were mainly on the nominal demand for money $M_{D}(t)=\phi_{D}(t) D(t)$.

${ }^{17}$ The Cambridgian approach places emphasis on the role of money as an asset among other assets and on the demand for money as depending, among other things, on the costs and returns from holding it instead of other assets. This emphasis is a characteristic of Keynes' liquidity preference theory (Keynes, 1936). It is also a central
} 
underlying the latter model (especially because it introduces a psychological time scale alongside the physical time scale).

One of the shortcomings of Cagan's model, Allais pointed out, is that it had only succeeded in representing the central period of the hyperinflations studied. Cagan's model fails to deal satisfactorily with the beginning ${ }^{18}$ and terminal stages. Furthermore, Allais added, Cagan had been no more successful than himself (in 1954) in finding a single formulation that applies to all the cases studied (Allais, 1966, p. 1125).

Allais claimed that the closeness of fit obtained by the HR formulation for periods of hyperinflations is better than that of Cagan. ${ }^{19}$ The HR formulation, he argued, can represent these periods through their whole course (Allais, 1986, p. 32). More importantly, the HR theory proposed a single formulation which covers both ordinary periods and hyperinflations. The results for both situations, as presented by Allais, appear to be exceptional (Allais, 1965, 1966).

These empirical results, however, sparked suspicions and criticisms ranging from misspecification (Cagan, 1969, pp. 429-430; Laidler, 1969, p. 104) to methodological error in the fitting procedure (Scadding, 1972). Allais replied to these criticisms (Allais, 1969; 1974, pp. 301-302; 1975). But, seemingly, he did not manage to dissipate the suspicions about his model and its empirical results. ${ }^{20}$

\footnotetext{
feature of Friedman (1956)'s restatement of the quantity theory and of Cagan (1956)'s model on the dynamics of hyperinflations.

${ }^{18}$ Cagan's failure to represent the beginning of hyperinflations is particularly linked to the fact that his model did not account for the variability of the rate of expectation (rate of memory decay) (See (Cagan, 1956, p. 60)).

${ }^{19}$ See (Allais, 1966, p. 1126 and p. 1142).

${ }^{20}$ It is not my aim here to pass under scrutiny the fitting procedure to confirm or disconfirm the remarkable quality of Allais' empirical results (Maybe several things could be said about it; for example, the fact that there is no analysis of the autocorrelation of the residuals). Nor is it my intention to discuss all the comments on and criticisms
} 
Alongside these criticisms, many economists emphasised Allais' innovative concept of psychological time. Most of them, as we will see, pointed out its role in determining coefficients in the model (i.e. the weighting coefficients). None of them, however, endeavoured to analyse the assumptions underlying its relation to physical time and their implication on the way the HR theory ought to be construed as a restatement of the quantity theory.

Cagan was one of the first economists to comment Allais' theory and to underscore the concept of psychological time. Like most of Allais' commentators, Cagan (1964 cited by Allais, 2001; 1969) analysed the HR formulation through the lenses of his own 1956 model. He thus interpreted the formulation of $Z(t)$ as an expectation pattern (namely, one of adaptive expectations) and he considered the rate $\chi(t)$ as a coefficient of expectation. When he commented the notion of psychological time, Cagan had in mind the role it plays in explaining the variation of the coefficient of expectation (rate of memory decay) in physical time. He thus stated that

[t]he effect of [psychological time] is to make [...] the constant "coefficient of expectation" a variable coefficient depending on the level of real cash balances. With this alteration, the exponential weights of past price changes, used to estimate the expected price change, have a changing pattern over time.[...] People thus look far back in time in forming expectations when changes have been slow, but pay more and more attention to recent events as the pace of change speeds up. [...](Cagan, 1964 cited by Allais 2001, p. 1058).

As we saw, this agrees with Cagan's finding about changes in the coefficient of expectation inasmuch as hyperinflation becomes more intense (and the relative demand for

\footnotetext{
levelled against the HR model. In this paper, I am mainly concerned with the study of Allais' conceptual framework in the light of a thorough analysis of the notion of psychological time. So, for my purpose, I will only focus on some comments on this notion and its place in Allais' model.
} 
money decreases). Cagan stated that 'Allais' concept of psychological time is a most ingenious way to take account of this phenomenon [...]' (Cagan, 1964 cited by Allais, 2001, p. 1058).

Friedman and Schwartz stressed the same idea, construing the HR formulation as an expectations-based model:

Allais argues that the rate at which people forget the past in judging the future -that is, the span of past time on which they base their anticipation- is variable and depends on the course of events themselves. If the relevant magnitude changes rapidly -for example, if prices change rapidly-then people also adapt their anticipations more rapidly, "forgetting" the past at a faster rate or using a smaller time span to form their anticipations, and conversely (Friedman and Schwartz, 1982, p. 358).

Like Cagan, Friedman and Schwartz were aware that Allais' explanation of the variation of the rate of memory decay is based on the notion of psychological time and its relation to physical time. None of these authors, however, paid due attention to the assumptions underlying this relation. ${ }^{21}$ Friedman and Schwartz put it this way: 'Allais proposes a very specific and sophisticated hypothesis to connect "psychological" time, as he calls it, with chronological time. For our purpose, the general idea rather than its specific embodiment is relevant' (Friedman and Schwartz, 1982, p. 358).

In the following section, I will attempt to give a thorough analysis of the concept of psychological time and the assumptions underlying its connection with physical time. I will

\footnotetext{
${ }^{21}$ One should note that whereas Cagan gave an extensive analysis of the HR theory, Friedman and Schwartz made only a comment about it (Friedman and Schwartz, 1982, p. 358). In this comment, they discussed the empirical validity of Allais' model in light of their own theory. They did not endeavour to understand the logical steps leading from Allais' premise to his conclusion. They did not try to replicate Allais' numerical applications. Nor did they apply his model to data of their own choice. Their comment, however, underscores an important feature of Allais' model (namely, the variability of the rate of memory decay) and, we will see, gives an insightful economic interpretation of the psychological time.
} 
show that there is in the HR theory more than what Cagan and Friedman and Schwartz pointed out, especially when it comes to reconsider it as a restatement of the quantity theory.

\section{The stability of the relative demand for money in the hereditary and relativistic reformulation of the quantity theory}

The stability of the relative demand for money (or that of the velocity of money) is in the thick of Friedman's restatement of the quantity theory. With Friedman (1956), the relative demand for money (or the velocity of money) is no longer considered as a constant magnitude. Rather, it is a variable that can be expressed as a stable function of a limited number of arguments. ${ }^{22}$ Cagan's model on the dynamics of hyperinflations is in the same vein.

The HR theory, as presented by Allais, seems to convey the same idea ${ }^{23}$-though its conceptual framework is quite different from that of Friedman and Cagan. A closer look at its assumptions will, nevertheless, show that it contains an original refinement of the notion of stability of the relative demand form money.

\footnotetext{
${ }^{22}$ I am focusing only on the theoretical aspect of Friedman's restatement. The empirical results related to this idea of a stable demand for money function will not be discussed here. For this issue, one could refer to Goldfeld (1989) who drew a rather gloomy picture about different attempts to specify a single function that appears empirically stable over the postwar period.

${ }^{23}$ This should not hide Allais' innovation recognised by Cagan and Friedman and Schwartz, among others. Indeed, in the HR theory, the relative demand for money is a function of the past rates of growth in aggregate nominal spending. As I explained earlier, Allais' innovation -underscored by his commentators- was to consider that the pattern of the weighting coefficients of these past rates is variable with time. The rate of memory decay is indeed variable. This rate, in its turn, depends on the past rates of growth of aggregate nominal expenditure (equations (17) and (5)).
} 
2.1 The invariance of the relative demand for money in psychological time and its variability in physical time

As I have previously explained, to determine how the rate of memory decay varies along the physical time scale, Allais had to connect psychological time with physical time. In order to do this, he assumed that the relative demand for money -the very magnitude- is invariant in psychological time.

The relative demand for money is a magnitude whose dimension is $t$. When it is calculated as the ratio of the nominal demand for money to the annual aggregate nominal spending, it measures the demand for cash balances in terms of months of aggregate nominal spending. If, for instance, it is equal to 0.25 , this means that the collectivity of economic agents, as a whole, desires to hold the equivalent of three months of its aggregate nominal spending as cash balances. Allais considered that the relative demand for money along the psychological time scale $\left(\phi_{D}^{\prime}\left(t^{\prime}\right)\right)$ is a constant. In other words, when referred to this time scale, the collectivity of economic agents desires to hold an amount of cash balances equivalent to a constant period of their aggregate nominal spending.

The relative demand for money in psychological time, $\Phi_{\mathrm{D}}^{\prime}\left(t^{\prime}\right)$, and its corresponding magnitude in physical time, $\Phi_{\mathrm{D}}(t)$, satisfy the following relation

$$
\Phi_{D}(t) d t^{\prime}=\Phi_{D}^{\prime}\left(t^{\prime}\right) d t \quad 24
$$

\footnotetext{
${ }^{24}$ To an instantaneous aggregate nominal spending in physical time, $D(t)$, corresponds an instantaneous aggregate nominal spending in psychological time, $D^{\prime}\left(t^{\prime}\right)$, such that $D(t) d t=D^{\prime}\left(t^{\prime}\right) d t^{\prime}$. The relative demand for money in psychological time is $\Phi_{D}^{\prime}\left(t^{\prime}\right)=\frac{M^{\prime}{ }_{D}\left(t^{\prime}\right)}{D^{\prime}\left(t^{\prime}\right)}$, where $M_{D}^{\prime}\left(t^{\prime}\right)$ is the nominal demand for money in psychological time. This latter magnitude has no dimension with reference to time (it is a stock variable). We have thus $M_{D}^{\prime}\left(t^{\prime}\right)=M_{D}(t)$ and then $\Phi_{\mathrm{D}}^{\prime}\left(\mathrm{t}^{\prime}\right)=\frac{\mathrm{M}_{\mathrm{D}}(t)}{\mathrm{D}^{\prime}\left(\mathrm{t}^{\prime}\right)}$. Substituting $D(t) \frac{d t}{d t \prime}$ for $D^{\prime}\left(t^{\prime}\right)$, we obtain the equation (18):
} 
Allais made the 'natural' assumption that, in a stationary regime $(Z(t)=0)$, the psychological time scale and the physical time scale are identical $\left(d t^{\prime}=d t\right)$. Put another way, in a stationary regime, physical durations equal psychological durations. ${ }^{25}$ Physical time flows at a speed of one unit of physical time per one unit of psychological time. The value of the relative demand for money in psychological time is thus equal to its value in physical time in a stationary regime:

$$
\Phi_{\mathrm{D}}^{\prime}\left(t^{\prime}\right)=\Phi_{0}, \quad \forall t^{\prime}
$$

This enables Allais to determine the ratio between psychological time and physical time $\left(d t^{\prime} / d t\right)$. Indeed, from equation (18), we have

$$
\frac{d t^{\prime}}{d t}=\frac{\Phi_{D}^{\prime}\left(t^{\prime}\right)}{\Phi_{D}(t)}
$$

and then, given (19),

$$
\frac{\mathrm{dt}^{\prime}}{\mathrm{dt}}=\frac{\Phi_{0}}{\Phi_{\mathrm{D}}(t)}
$$

This leads, given equations (11) and (14), to the relation (16)

$$
\frac{\mathrm{dt}^{\prime}}{\mathrm{dt}}=\frac{1+e^{Z(t)}}{2}
$$

Now, let us observe the monetary behaviour of economic agents as described by the HR theory.

$$
\Phi_{\mathrm{D}}(\mathrm{t}) \mathrm{dt}^{\prime}=\Phi_{\mathrm{D}}^{\prime}\left(\mathrm{t}^{\prime}\right) \mathrm{dt}
$$

\footnotetext{
${ }^{25}$ There is no psychological distortion of time.
} 
In physical time, we see the collectivity of economic agents, as a whole, behaving according to its appraisal of economic conjuncture. This appraisal is a function of the memory the collectivity keeps of past rates of growth in aggregate nominal spending $x(t)$. This memory fades with time, but unevenly (the rate of memory decay $\chi(t)$ is variable). We see economic agents reducing their money balances in relation to their aggregate nominal spending when the conjuncture proves to be good. We see them increasing these balances in bad economic conjuncture. We see them "running away" from money in periods of hyperinflation. And we see them preferring to hold cash balances in periods of depression.

Let us observe the same "sequences" in psychological time. The appraisal of economic conjuncture by the collectivity as a whole depends on the memory of past rates of growth in aggregate nominal spending $x^{\prime}\left(t^{\prime}\right)$. This memory fades with time but on a regular basis (the rate of memory decay $\chi^{\prime}$ is constant). ${ }^{26}$ We see economic agents in different circumstances (periods of stability, deflation, hyperinflation...) tending to maintain the same ratio between their cash balances and their aggregate nominal spending. This ratio is equal to $\Phi_{0}$.

${ }^{26}$ With reference to the psychological time scale, the expression of the coefficient of psychological expansion takes the following invariant form:

$$
Z^{\prime}\left(t^{\prime}\right)=\int_{-\infty}^{t^{\prime}} x^{\prime}\left(\tau^{\prime}\right) e^{-\chi^{\prime}\left(t^{\prime}-\tau^{\prime}\right)} d \tau^{\prime}
$$

with

$$
x^{\prime}\left(t^{\prime}\right)=x(t) \frac{d t}{d t^{\prime}}
$$


What does this mean?

The invariance of the relative demand for money along the psychological time scale means that its variations along the physical time scale depend on the relation between both time scales. It is as if the overall appraisal of economic conjuncture only distorts the ratio of physical time to psychological time entailing thereby the variation of the relative demand for money along the physical time scale. We can therefore say that the HR theory provides an explanation of the variability of the relative demand for money along the physical time scale by the psychological distortion of time:

$$
\Phi_{D}(t)=\Phi_{0} \frac{d t}{d t^{\prime}}
$$

with

$$
\frac{\mathrm{dt}}{\mathrm{dt}^{\prime}}=\frac{2}{1+e^{Z(t)}}
$$

We know, however, that it is the statement of the invariance of the relative demand for money in psychological time that enables Allais to measure the psychological distortion of time $\left(d t / d t^{\prime}\right)$. It is then necessary to question the status of this statement. For, if it is a convention which defines the psychological time scale, explaining the variability of $\Phi_{D}(t)$ by the psychological distortion of time would be a mere tautology. If it is rather a hypothesis that can be subject to empirical test, "the invariance of the relative demand for money in psychological time" could be considered as a regularity supported by numerical evidence. The resulting explanation of the variability of $\Phi_{D}(t)$ could then be considered as stemming from empirical data.

The question I pose here is: To what extent the empirical test of the HR formulation could be considered as supporting or refuting "the invariance of the relative demand for money 
in psychological time"? This question is thus about the hypothetical status of this statement. And it is clear that to answer it, one need to examine Allais' conception of psychological time.

2.1.1 The convention in the definition of the psychological time scale. In his 'Traité d'économie pure', Allais (1943) devoted some pages to the subject of measurement scales. He explained that the way we measure time, in general, is conventional (Allais, 1943, p. 225). Allais argued, quoting Poincaré, that

[t]here is no one way of measuring time more true than another; that which is generally adopted is only more convenient. Of two watches, we have no right to say that the one goes true, the other wrong; we can only say that it is advantageous to conform to the indications of the first (Poincaré cited by Allais, 1943 , p. 230). ${ }^{27}$

The astronomical time scale is used 'because it makes the formulae of mechanics particularly simple' (Allais, 1943, p. 230). It is, from this point of view, 'implicitly defined' (ibid.) by these formulae. We can claim that the same logic applies for the psychological time scale. It is a time scale conceived such that the formulation of the hereditary law becomes invariant. It can thus be considered as implicitly defined by this law.

The conception of a time scale based on the condition of a constant rate of memory decay is, therefore, a matter of a judicious choice based on the formulation of the hereditary law. It is a mere convention which leads to the invariance (and thus the simplicity) of this formulation. 2829

\footnotetext{
${ }^{27}$ The translation is that of Halsted in (Poincaré, 1907, p. 30).

${ }^{28}$ See equation (22).

29 'The distinction between the psychological time scale and physical time corresponds simply to a transformation of the time scale so as to render certain relations invariant' (Allais, 1974, p. 322).
} 
2.1.2 The hypothetical status of "the invariance of the relative demand for money in psychological time”. The psychological time scale is, as I noted above, defined by a constant rate of memory decay. Now, let me raise a question: Is there a reason why the relative demand for money should be constant along this psychological time scale? The answer is: None, $a$ priori. The idea of a context-dependent perception of time does not have as a logical consequence the invariance of the relative demand for money in psychological time. Indeed, even if we take into account this intuitive idea, nothing prevents us to conceive of the relative demand for money as a variable magnitude when referred to the psychological time scale.

To state that the relative demand for money is constant along the psychological time scale is to assume that it varies along the physical time scale in inverse proportion to the ratio $\left(d t^{\prime} / d t\right)$

$$
\phi_{\mathrm{D}}(\mathrm{t})=\phi_{\mathrm{D}}^{\prime}\left(t^{\prime}\right) \frac{\mathrm{dt}}{\mathrm{dt}^{\prime}}
$$

$$
\text { With } \quad \phi_{D}^{\prime}\left(\mathrm{t}^{\prime}\right) \text { constant, } \forall \mathrm{t}^{\prime}
$$

We know, besides, that the rate of memory decay varies along the physical time scale proportionally to the ratio ( $\left.d t^{\prime} / d t\right)$, as expressed through equation (15)

$$
\chi(\mathrm{t})=\chi^{\prime}\left(t^{\prime}\right) \frac{\mathrm{dt}^{\prime}}{\mathrm{dt}} \quad\left(\text { with } \chi^{\prime}\left(t^{\prime}\right) \text { constant, } \forall \mathrm{t}^{\prime}\right)
$$

Ultimately, this amounts to admitting that the rate of memory decay $\chi$ varies in physical time in inverse proportion to the relative demand for money $\phi_{D}$ (Allais, 1965, p. 76): 


$$
\chi(t)=\frac{\chi^{\prime}\left(t^{\prime}\right) \phi_{D}^{\prime}\left(t^{\prime}\right)}{\phi_{D}(t)}
$$

(with the product $\left(\chi^{\prime}\left(t^{\prime}\right) \phi_{\mathrm{D}}^{\prime}\left(\mathrm{t}^{\prime}\right)\right)$ constant, $\left.\forall \mathrm{t}^{\prime}\right)$

And this is the kind of inverse relationship Allais induced from empirical data in his 1954 work -and Cagan (1956) alluded to on his work on hyperinflations- and which the HR model is supposed to capture.

As equation (27) shows, to get this inversely proportional relationship between the rate of memory decay and the relative demand for money, we "only" need to assume that the product $\chi^{\prime}\left(t^{\prime}\right) \phi_{\mathrm{D}}^{\prime}\left(t^{\prime}\right)$ is constant. But when we take into account the conventional definition of the psychological time scale through a constant rate of memory decay, $\chi^{\prime}\left(t^{\prime}\right)$, the aforesaid relationship appears as a logical consequence of the invariance of the relative demand for money in psychological time $\left(\phi_{\mathrm{D}}^{\prime}\left(t^{\prime}\right)\right)$.

Equation (27) leads to express the rate of memory decay as a function of the rate of psychological expansion $Z(t)$. Indeed, by substituting (19) into (27), we find

$$
\chi(\mathrm{t})=\chi^{\prime}\left(t^{\prime}\right) \frac{\phi_{0}}{\phi_{\mathrm{D}}(t)}
$$

This leads, given (11) and (14), to equation (17) expressing the behaviour of the rate of memory decay in physical time:

$$
\chi(\mathrm{t})=\chi^{\prime}\left(\mathrm{t}^{\prime}\right) \frac{1+e^{Z(t)}}{2}
$$

So, in the final analysis, the statement of "the invariance of the relative demand for money in psychological time" allows to determine how the rate of memory decay $\chi$ varies in physical time. 
This "invariance" is then a hypothetical statement subject to empirical test in the framework of the HR formulation of the demand for money. It is an assumption that can be tested empirically through its consequences (namely, the way the rate of memory decay in the HR formulation varies in physical time). Let me emphasise here that I am not claiming that the invariance assumption can be empirically tested as an isolated statement. The HR formulation is in fact based on a set of assumptions, including that of the invariance of $\phi^{\prime}{ }_{\mathrm{D}}\left(t^{\prime}\right)$. The fitting of the HR formulation to data amounts to a joint test for all of them. ${ }^{30}$ Besides, Allais' aim was to test the HR formulation of the demand for money as a whole, not only the statement of the invariance of the relative demand for money in psychological time. The point I want to make through the previous analysis is that, while reading the HR theory, we should take into account the hypothetical status of the latter statement. And once that is done, the substance of the HR theory reads as follows:

(i) Firstly, the relative demand for money is invariant in psychological time.

(ii) Secondly, the psychological appraisal of economic conjuncture "distorts" the ratio of physical time to psychological time. Variation of the relative demand for money in physical time is nothing else than the expression of this distortion.

Demonstrating that the first assertion is not a convention but an assumption subject to empirical test, I prove that the resulting explanation (second assertion) is not a tautology but an explanation closely related to facts. It was suggested by empirical data and it can be put to test through the HR formulation of the demand for money.

An in-depth study of Allais' restatement of the quantity theory shows therefore that, in the final analysis, this restatement amounts to a theory of time. It is specifically a theory of psychological time and its relation to physical time. In the HR theory, indeed, the explanation

\footnotetext{
${ }^{30}$ This is related to the Duhem thesis.
} 
of the behaviour of the relative demand for money amounts to an explanation of the ratio of physical time to psychological time.

Now, another step should be taken in order to further our understanding of the nature of Allais' restatement of the quantity theory. And this step is about the nature of psychological time beyond the convention that defines it.

\subsection{An inquiry into the nature of psychological time}

The previous analysis shows that the HR theory provides an original explanation of the behaviour of the relative demand for money. This explanation has a major implication on the notion of time in the study of monetary and maybe other social phenomena. This implication would be similar to that resulting from the theory of relativity in physics.

Allais, indeed, contended that '[t]he analogy between the theory proposed here and the theory of relativity is clear; and although different fields are concerned, the consideration of psychological time meets the same need as the consideration of $\mathrm{ds}^{2}$ in the theory of relativity' (Allais, 1974, p. 322). ${ }^{31}$ This analogy is recurrent in his writings (Allais 1965, p. 23; 1974, p. 322; 2001, p. 49). And this is not surprising, given his profile. Indeed, Allais is an economist and a physicist. He did recognised research in physics. ${ }^{32}$ In his work in economics, Allais did not have any inferiority complex vis-à-vis the tool-rich physicists. Rather, he had a tendency to

\footnotetext{
${ }^{31}$ As we will see below, the theory of relativity (special and general) states that the measure of a time interval (and that of a distance) between two events depends on the frame of reference in which these events are recorded. $\mathrm{ds}^{2}$ is a spacetime interval. It is a combination of space and time quantities. Its value is invariant whatever the frame of reference.

32 In 1959, Maurice Allais was awarded the Galabert Prize of the "Société Française d'Astronautique" and the Prize of the Gravity Research Foundation (USA).
} 
explain economic phenomena using analogies with physical phenomena and physical theories. Munier wrote in a comment of the HR theory:

One could venture to say that Allais finds traditional money demand theory too close to classical mechanics and, although he is fond of physics, wants all the same to look within that discipline for a more sophisticated inspiration to his theory: he finds it in relativity theory (Munier, 1991, p. 195).

The reference made by Allais the economist to the theory of relativity may however appear disconcerting to those who know that Allais the physicist was an ardent critic of this theory and its author. Indeed, Allais casted doubt on Einstein's paternity of the theory of relativity (Allais, 2005). And an important part of his work in physics could be described as an attempt to discredit this theory by proving that some of its assumptions are contradicted by experiments $^{33}$ (Allais, 2004) ( $^{34}$. This, however, did not prevent him from drawing his inspiration from it (and quoting Einstein) when he conceived his HR theory of the demand for money.

The coexistence of these two conflicting attitudes in Allais (anti-relativistic in physics and pro-relativistic in economics) is not as paradoxical as it appears. Indeed, one could say that Allais was not hostile to the theory of relativity as a logical framework. But for him, the criterion of experiments and empirical test is prominent. Allais rejected the theory of relativity in physics because -according to him- some of its assumptions are contradicted by experiments. He retained the idea of relativity and applied it in economics because he found it empirically fruitful.

Most of Allais' commentators overlooked the analogy Allais made between his HR theory and the theory of relativity. Some of them only referred to it. But none endeavoured to

\footnotetext{
${ }^{33}$ Clearly, Allais' attack on the theory of relativity did not convince the scientific community.

${ }^{34}$ It is important to note that the first experiments, undertaken by Allais, that contradict assumptions of the theory of relativity date back to the 1950 s, quite before the first publications of the HR theory.
} 
explore it. In explaining the idea of a context-dependent perception of time, Barthalon (2014) quoted Einstein's statement 'An hour [in physical time] talking with a pretty girl sitting on a park bench passes like a minute [in psychological time], but a minute [in physical time] sitting on a hot stove seems like an hour [in psychological time]' 35 (Einstein cited by Barthalon, 2014, pp. 71-72). The reference to Einstein is certainly relevant here. I would even say that one could go one step further and draw upon Einstein's theory of relativity in order to get an instructive idea about psychological time in Allais. It would then be relevant to take a look at the theory of relativity in order to explore the "clear" analogy mentioned by Allais, to understand what would be self-evident to Allais the physicist but less obvious to the economist trying to analyse his monetary theory.

2.2.1 Time in physics. In pre-relativistic (Newtonian) physics, time was considered as the frame of physical phenomena. It was an absolute time, flowing uniformly and without relation to space. Time and space were, in Newtonian conception, independent of each other and of the phenomena of which they constitute the frame. A time interval between two events was considered as independent of the frame of reference to which the observer is related. ${ }^{36}$

This conception underwent two major transformations. The first one was in the special theory of relativity. In this theory, Einstein considered the measure of a time interval as dependent on the frame of reference to which the observer is related (Einstein, 1923, p. 30). Two simultaneous events relatively to a given frame of reference (i.e. the time interval between the two events is equal to zero) would appear to be not simultaneous (i.e. the time interval

\footnotetext{
${ }^{35}$ Terms in the square brackets are added by Barthalon as notes in his book (Barthalon, 2014, p. 354). They specify the time scales to which Einstein is implicitly referring in this quotation.

${ }^{36}$ Independent of its state of motion and its position with respect to the matter the space contains.
} 
between the two events is not equal to zero) relatively to another frame of reference in a state of uniform translation relatively to the first frame (ibid., pp. 61-62). Time was thus deprived from its independence of space (ibid.). The conception of space and time as two independent continua was abandoned in favour of a new conception of a single continuum of space-time. The reformulation of the concepts of space and time in the special theory of relativity was made according to general laws of physical phenomena ${ }^{37}$ (Paty, 1993). Nevertheless, the space-time kept independence with regard to these phenomena: These phenomena do not entail any modification on it.

Time (along with space) underwent a more fundamental transformation in the general theory of relativity. In a universe where gravitational fields (whose effect is to accelerate matter) are omnipresent, it became clear that the special theory of relativity (which is related to nonaccelerated frames of reference) is not a good theory of the universe.

Einstein was led to unify the special theory of relativity and the gravitation theory in the frame of the general theory of relativity (Barberousse, 2011). The key of this unification is a reformulation of space-time which gives an original interpretation of the gravitation phenomenon. The latter is no longer explained as a force exerted between objects in (contents of) the universe. Rather, it is expressed as a geometrical property of the universe (the container) (Luminet, 1993).

Space-time is curved, deformed by the matter it contains (ibid.). The flow of time is influenced not only by the state of motion of the frames of reference to which the observers are related (the special theory of relativity) but also, and mainly, by the intensity of gravitational fields generated by the matter and in which these observers are immersed (Lachièze-Rey, 1993). These gravitational fields do not allow time to "flow uniformly", so to speak (Paty, 1993). The

\footnotetext{
${ }^{37}$ It aimed at reconciling the principle of relativity (related to inertial motion) and the law of propagation of light.
} 
flow of time depends on the distribution of the matter - which generates gravitational fields- in space-time. Time dilates in a strong gravitational field and contracts in a weak gravitational field.

Thus, if in the special theory of relativity, space and time lose their objectivity in favour of a single continuum of space-time, in the general theory of relativity, the space-time loses its objectivity in favour of the space-time-matter (Schlick, 1929, p. 69). Space-time filled with matter is no longer an absolute frame (Luminet, 1993). It is no longer a container separate from the matter it contains, independent of phenomena this matter generates. Rather, it is a container the form of which is influenced by its 'contents' (i.e. the matter which generates gravitational fields) (Paty, 1993).

2.2.2 Time in the HR theory. Certainly, it is absurd to claim that we can draw a perfect parallel between time transformation in the general theory of relativity and time transformation in the HR theory. Indeed, the former is grounded on physical phenomena, the latter on monetarypsychological phenomena. Nevertheless, it is clear that the idea of time non-independence in the former theory is also present, but in a different form, in the latter.

Allais, as we saw, started from the intuitive idea that the perception of time could not be the same for economic agents in a period of stability as in a period of substantial fluctuations in prices and aggregate nominal spending. He then defined a psychological time scale based on the convention of a constant rate of memory decay. And he assumed that the relative demand for money is invariant along this scale. The variation of this magnitude when referred to the physical time scale is proportional to the distortion of the ratio $\left(d t / d t^{\prime}\right)$. This enabled Allais to determine the expression of this ratio. The latter (as equation (25) shows it) depends on the psychological appraisal of the economic conjuncture measured by the coefficient $Z(t)$ : 


$$
\frac{\mathrm{dt}}{\mathrm{dt}^{\prime}}=\frac{2}{1+e^{Z(t)}}
$$

Thus, as in physics the measure of time depends mainly on the intensity of the gravitational field in which the frame of reference is situated, in monetary psychology, the measure of time depends on the economic conjuncture within which economic agents operate. Therefore, if 'Einstein stated [...] that one should not talk about the "duration of an event" without another specification, but about the "duration with respect to a particular system of reference" ' (Allais, 1965, p. 23), one could say that in monetary psychology, one should not talk about a duration of an event without another specification, but about a duration with respect to a given economic conjuncture.

Time, at the level of monetary psychology, is thus deprived from its independence with respect to economic conjuncture. And as in physics space-time loses its objectivity in favour of the space-time-matter, in monetary psychology, time (physical time) loses its objectivity in favour of the time-economic conjuncture, namely the psychological time:

$$
\mathrm{dt}^{\prime}=\frac{1+e^{Z(t)}}{2} \mathrm{dt}
$$

Psychological time is a dynamic entity, a 'container' influenced by phenomena (variations in the aggregate nominal spending) that occur within it.

In his comment of the transformation of psychological time scale in Allais' theory, Cagan (1969) gave an explanation which clearly expresses this idea:

What we are doing in the transformation is treating each one of a variety of economic developments as a unit, with less emphasis on how long they last. People know that trends and cycles exist in economic life. They know that a certain stage of the cycle will be followed by another stage which by past experience will bear a certain expected relation to the preceding and following stage. The 
length of each stage may be far less important than the total change occurring during the stage. Long stages may not deserve any more (or proportionately more) weight, in judging future events, than short stages (Cagan, 1969, pp. 428-429).

Friedman and Schwartz's interpretation of the time transformation in Allais' theory conveys the same idea of :

A lengthy cycle phase means that economic events have been proceeding slowly, a brief cycle phase means that they have been proceeding rapidly. [...] The time period corresponding to the length of a phase, or to the interval between phases, might therefore come closer to representing a constant duration of psychological time than would a fixed chronological time interval (Friedman and Schwartz, 1982, p. 358).

\subsection{The HR theory: an ontological restatement of the quantity theory}

The hereditary and relativistic restatement of the quantity theory, as I attempted to present it, is therefore based on a fundamental transformation of time. I first showed that, according to this restatement, the variation of the relative demand for money in physical time is the expression of a distortion in the ratio between physical time and psychological time. Exploring the analogy mentioned by Allais between his theory and the relativity theory, I showed that it is psychological time (time as perceived by the collectivity of economic agents), and not physical time, which constitute an absolute frame of reference. This result could be subject to an interpretation in terms of the theory's ontology. Indeed, one could argue that, in the HR theory, physical time is not an ontological entity: it is not part of the fundamental building blocks of the world that the theory describes. It is rather psychological time that has the status of an 
ontological entity in that it constitutes the fundamental flow of time in the economy. ${ }^{38}$ The HR theory could be thus construed as an ontological restatement of the quantity theory of money. Let me explain what is meant by "ontological restatement".

In physics, when a law is contradicted by facts, two solutions are possible. The first solution is "legislative". ${ }^{39}$ It consists in replacing the first law by another law which better corresponds to facts. The second solution is ontological. It consists in considering the idea that maybe it is not the law which is contradicted by facts but our interpretation of facts which is not the good interpretation, and that if we complete our starting ontology (i.e. the set of ontological entities on which we ground our explanation) the contradiction between the law and facts may dissipate. The ontological solution consists in completing the ontological furniture ${ }^{40}$ through adding new kind of entities. ${ }^{41}$

Now, let us get back to our field and try to apply the previous distinction to the quantity theory of money. We know that this theory is, in its traditional version, based on the assumption of a constant relative demand for money (or a constant velocity of circulation). This assumption was completely contradicted by empirical data. The solution proposed by Friedman (1956) to restore the quantity theory could be considered as a legislative solution in the sense that it entails a change in the model that describes the behaviour of the relative demand for money. The HR

\footnotetext{
${ }^{38}$ Let me emphasise that the ontological interpretation of psychological time I am making here is specific to my analysis of the HR theory. I do not claim that I inferred it from the ontological interpretation of space-time or space-time-matter in the relativity theory. For, the question of the ontology of space-time in the latter theory is much more complicated. And its study is beyond the scope of this paper.

${ }^{39}$ It is called the legislative solution ('[...]la solution du problème est de nature législative' (Klein, 2015, p. 20)) because it is related to the laws (of physics).

${ }^{40}$ In french 'le mobilier ontologique' (Klein, 2015, p. 39).

${ }^{41}$ See Cohen-Tannoudji and Klein (2012) and Klein (2015).
} 
theory, as my analysis shows, may rather be considered as an ontological reformulation of the quantity theory. This reformulation states that the fact that the assumption of a constant relative demand for money is contradicted by facts does not mean that this magnitude is intrinsically variable. Rather, it is our interpretation of facts which is not the good interpretation. The relative demand for money is a psychological magnitude which is intrinsically constant along a psychological time scale. Its variability with reference to the physical time scale is only the effect of changes in the ratio between physical time and psychological time. The main ontological transformation underlying this reformulation consists in replacing physical time in the starting ontology (i.e. in the initial set of ontological entities) with a new entity, namely the psychological time.

This interpretation could, however, be subject to an objection. Indeed, if one claims that Allais' restatement is "ontological" without further explanation, it could be understood that this restatement rests only on the consideration of psychological time. It could be understood that there is not any transformation of a "legislative" kind in his model -for example, a change in the form of the demand for money function, its arguments, ... This is clearly not true. One need only look to the set of equations that constitute the HR formulation to be convinced of that.

The claim that the HR theory may be considered as an ontological restatement of the quantity theory is grounded in two arguments. The first one is that the centerpiece of this restatement is ontological. It is the consideration of psychological time as the fundamental flow of time in the economy. The second argument is that the "legislative" part of the restatement constitutes -in the final analysis- a model that explains the relation of psychological time to physical time. 


\section{Conclusion}

In this paper, I attempted to throw light on Allais' unrecognised restatement of the quantity theory of money. I tried to assess its contribution on the crucial issue of the stability of the relative demand for money (or that of the money velocity).

My analysis focused on the concept of psychological time. I tried to go beyond what Allais' commentators underscored about the role of this concept in his model. I wanted my interpretation of Allais' restatement to be true to his conception of economics as a science destined to the search of regularities. And I wanted it to take into account his tendency, as a physicist-economist, to explain economic phenomena through analogies with physical phenomena and theories.

Thorough analysis of the concept of psychological time and the assumptions relating it to physical time enabled me to show that, compared to the traditional version and to Friedman's restatement of the quantity theory, Allais' restatement carried the notion of stability of the relative demand for money a notable step further: In Allais, the relative demand for money is a constant magnitude along the psychological time scale. Its variation when referred to the physical time scale is the expression of the distortion in the ratio between physical time and psychological time.

This analysis shows that Allais' HR theory of the demand for money amounts to a theory of time. It allowed me to underscore the notion of psychological time as the hallmark of Allais' restatement of the quantity theory and to emphasise thereby the ontological nature of this restatement.

Allais was not concerned with ontological issues -and economists in general seldom address these issues. But when he questioned the independence of time with regard to the course of economic events, his questioning had an ontological flavour. This paper shows that it led him to a restatement of the quantity theory of another kind, so to speak. Given its ontological 
nature and the original refinement of the notion of stability it contains, it would not be going too far to say that Allais' restatement might have been considered as an important chapter in the quantity theory's book rather than barely mentioned in a footnote.

\section{References}

Allais, M. (1943) [1994]. Traité d'économie pure [A Treatise of Pure Economics]. Paris : Éditions Clément Juglar.

Allais, M. (1956). Explication des cycles économiques par un modèle non linéaire à régulation retardée [An Explanation of Economic Cycles by a Non-linear Model with Lagged Regulation]. Metroeconomica, 8(1), 4-83.

Allais, M. (1965). Reformulation de la théorie quantitative de la monnaie [A Restatement of the Quantity Theory of Money]. Bulletin Sedeis, 928(Suppl.), S1-S186.

Allais, M. (1966). A Restatement of the Quantity Theory of Money. American Economic Review, 56(5), 1123-1156.

Allais, M. (1969). Growth and Inflation: A Reply to the observations of the discussants by Maurice Allais. Journal of Money, Credit and Banking, 1(3), 441-462. 
Allais, M. (1974). The Psychological Rate of Interest. Journal of Money Credit and Banking, 6(3), 285-331.

Allais, M. (1975). The Hereditary and Relativistic Formulation of the Demand for Money: Circular Reasoning or a Real Structural Relation?. The American Economic Review, $65(3), 454-464$.

Allais, M. (1986). The Empirical Approaches of the Hereditary and Relativistic Theory of the Demand for Money: Results, Interpretation, Criticisms, and Rejoinders. Economia della Scelte Pubbliche, Journal of Public Finance and Public Choice (Fondazione Luigi Einaudi), 4(1), 3-83.

Allais, M. (1997). An Outline of My Main Contributions to Economic Science. The American Economic Review, 87(6), 3-12.

Allais, M. (2001). Fondements de la dynamique monétaire [Foundations of Monetary Dynamics]. Paris : Éditions Clément Juglar.

Allais, M. (2004). L'effondrement de la théorie de la relativité ; Implication irréfragable des données de l'expérience [The Collapse of the Theory of Relativiy ; Irrefutable implication of experimental data]. Paris : Éditions Clément Juglar. 
Allais, M. (2005). Albert Einstein : Un extraordinaire paradoxe [Albert Einstein : An Extraordinary Paradox]. Paris : Éditions Clément Juglar.

Barberousse, A. (2011). Philosophie de la physique [Philosophy of Physics]. In A. Barberousse, D. Bonnay \& M. Cozic (Eds.), Précis de philosophie des sciences [Handbook of Philosophy of Science] (pp. 350-377). Paris: Vuibert.

Barthalon, E. (2014). Uncertainty, Expectations, and Financial Instability; Reviving Allais' Lost Theory of Psychological Time. New York, NY: Columbia University Press.

Cagan, P. (1956). The Monetary Dynamics of Hyperinflation. In M. Friedman (Ed.), Studies in the Quantity Theory of Money (pp. 25-117). Chicago, IL: University of Chicago Press.

Cagan, P. (1969). Allais' Monetary Theory: Interpretation and Comment. Journal of Money, Credit and Banking, 1(3), 427-432.

Cohen-Tannoudji, G., \& Klein, E. (2012). Les neutrinos défient les physiciens [Neutrinos challenge physicists], La Recherche, 38 .

Einstein, A. (1923). La théorie de la relativité restreinte et générale [Relativity: The Special and the General Theory]. Paris: Dunod.

Friedman, M. (1956). The Quantity Theory of Money: A Restatement. In M. Friedman (Ed.), Studies in the Quantity Theory of Money (pp. 3-21). Chicago, IL: University of Chicago Press. 
Friedman, M., \& Schwartz, A.J. (1963). A Monetary History of the United States, 1867-1960. Princeton, NJ: Princeton University Press.

Friedman, M., \& Schwartz, A.J. (1982). Monetary Trends in the United States and the United Kingdom, Their Relation to Income, Prices, and Interest Rates, 1867-1975. Chicago, IL: The University of Chicago Press.

Goldfeld, S.M. (1989). Demand for Money: Empirical Studies. In J. Eatwell, M. Milgate \& P. Newman (Eds.), Money (pp. 131-143). London, UK: The Macmillan Press Limited.

Keynes, J.M. (1936) [1973]. The General Theory of Employment, Interest and Money. Cambridge, UK : The Macmillan Press LTD for The Royal Economic Society.

Klein, É. (2015). L'avenir de la conquête du minuscule [The Futur of the Conquest of the minuscule]. Études, 2015/7, 33-44.

Lachièze-Rey, M. (1993) [2013]. Ả la recherche du Temps Cosmique [Searching for the Cosmic Time]. In É. Klein \& M. Spiro (Eds.), Le Temps et sa flèche [The Time and Its Arrow] (pp. 81-92). Malesherbes : Flammarion.

Laidler, D. (1969). The Demand for Money: Theories and Evidence. Scranton, PA: International Textbook. 
Luminet, J.P. (1993) [2013]. Matière, Espace, Temps [Matter, Space, Time]. In É. Klein \& M. Spiro (Eds.), Le Temps et sa flèche [The Time and Its Arrow] (pp. 59-80). Malesherbes : Flammarion.

Munier, B. (1991). Nobel Laureate: The Many Other Allais Paradoxes. The Journal of Economic Perspectives, 5(2), 179-199.

Paty, M. (1993) [2013]. Sur l'histoire du problème du Temps, le Temps physique et les phénomènes [On The History of the Problem of Time, Physical Time and Phenomena]. In É. Klein \& M. Spiro (Eds.), Le Temps et sa flèche [The Time and Its Arrow] (pp. 2158). Malesherbes : Flammarion.

Poincaré, H. (1907). The Value of Science. (G.B. Halsted, Trans.). New York, NY : The Science Press.

Prat, G. (1999). Temps psychologique, oubli et intérêt chez Maurice Allais [Psychological Time, Forgetfulness and Interest in Maurice Allais]. Recherches Economiques de Louvain, 65(2), 179-206.

Scadding, J. L. (1972). Allais' Restatement of the Quantity Theory of Money: Note. The American Economic Review, 62(1/2), 151-154.

Schlick, M. (1929). Espace et temps dans la physique contemporaine [Space and Time in Contemporary Physics]. Paris : Gauthiers Villars et Cie Éditeurs. 